\title{
Los salazones de Algeciras y cómo la incoación de un BIC obliga a indemnizar al promotor. El informe pericial en la valoración de los perjuicios
}

Jaime Hernández Vaillo, letrado de la Junta de Andalucia, adjunto a la Jefatura de Asuntos Contenciosos

\section{INTRODUCCIÓN}

El hallazgo de un resto arqueológico siempre es motivo de satisfacción, tanto por haber descubierto un pedazo de historia que permaneció oculto y enterrado durante siglos, como por el premio económico que implica. Pero cuando este hecho tiene lugar durante la realización de una obra privada, los efectos que de ello se derivan son bien distintos. La expansión física de los municipios, el inmenso despliegue urbanizador imperante en los últimos años, unido a la crisis económica, han provocado la súbita aparición de una casuística hasta ahora casi estéril en materia de responsabilidad patrimonial de las administraciones públicas, dentro del ámbito del patrimonio histórico.

Debido a ello, esta proliferación de reclamaciones también ha generado una exigua pero suficiente doctrina jurisprudencial, portadora de ciertos criterios muy a tener en cuenta a la hora de admitir la necesidad de indemnizar a los propietarios que resulten afectados por hallazgos arqueológicos, en la medida en que estos descubrimientos pueden limitar total o parcialmente el derecho a edificar. Con carácter general, esta doctrina viene a determinar que los particulares no están obligados a soportar las restricciones impuestas tras el hallazgo en beneficio de la comunidad, a expensas de su solo patrimonio. Más aún cuando éste no se produce dentro de un entorno arqueológico preexistente y protegido por el planeamiento urbanistico, que advierte al propietario de posibles limitaciones futuras, sino que supone la declaración primigenia de un bien de interés cultural (BIC).

\section{EL HALLAZGO: LOS SALAZONES DE ALGECIRAS}

Un ejemplo paradigmático en estos casos es el de las dos factorías romanas de salazones de Algeciras (Cádiz), ubicadas en el sector denominado Villa Vieja, que el Decreto 231/2003, de 18 de noviembre, del Consejo de Gobierno, declaró BIC con la categoría de zona arqueológica. El expediente se inició el 27 de mayo de 2002, como consecuencia de una intervención de urgencia, encontrándose ocho piletas de maceración de garum, vestigio de la colonia romana fundada en el último tercio del siglo I a. de C., proveniente de efectivos del norte de África. Estas factorias, que presentan un estado de conservación excepcional, tenían como finalidad la limpieza y el procesado de pescado para la elaboración de salsas, y sufrieron diversas reformas, ampliaciones y cambios de uso durante sus 500 años de funcionamiento. La zona arqueológica quedó delimitada a un área poligonal, llevando aparejada la adecuación del planeamiento a la protección de la misma, conservándose la totalidad de los restos in situ.

La declaración como BIC de estas factorías romanas impidió a una empresa promotora la ejecución de un proyecto para la construcción de 28 viviendas. Todo comenzó cuando, durante las obras, se descubrieron unos restos romanos que a la postre serían los propios salazones. Mientras se llevaban a cabo las labores de prospección arqueológica, el Ayuntamiento de Algeciras retrasó el expediente de la licencia urbanistica, a la espera de que la Consejería de Cultura y la promotora llegaran a un acuerdo que nunca cuajó. Finalmente fue concedida la licencia, pero apenas un mes después se produjo la declaración de BIC, truncándose la posibilidad de edificar.

Para resarcir los graves perjuicios económicos causados, se instó una indemnización por responsabilidad patrimonial de la Administración, que fue denegada por la Consejería. Tras un intenso procedimiento contencioso-administrativo, el Tribunal Superior de Justicia con sede en Sevilla desestimó el recurso en sentencia de fecha 29 de diciembre de 2008. Sin embargo, posteriormente, en casación, el Tribunal Supremo, en sentencia de 15 de diciembre de 2010, reconoció la procedencia de dicha responsabilidad patrimonial al entender que la declaración de BIC impedía al propietario hacer suyo el aprovechamiento urbanístico. Este concepto, ligado al derecho de propiedad, se define como el derecho potencial a construir según las condiciones impuestas por el planeamiento. 0 lo que es lo mismo, la facultad de edificar en un terreno.

La aludida sentencia del Alto Tribunal es de una innegable trascendencia, porque viene a hacer depender el nacimiento de la responsabilidad patrimonial con el derecho a "materializar" el 
aprovechamiento urbanístico, si éste ya existía con anterioridad a la declaración del BIC. Es decir, la mera expectativa urbanistica se transforma en un auténtico derecho adquirido cuando al titular del terreno, dentro del proceso urbanizador, le es concedida la correspondiente licencia municipal para edificar. El valor del suelo ya no estaria integrado únicamente por el del solar, sino además, por el derecho a construir, debiendo indemnizarse cuando por aplicación de las normas en materia de patrimonio histórico se restringe ese derecho.

\section{LA INDEMNIZACIÓN: ASPECTOS QUE INFLUYEN}

La claridad de la conclusión a la que llega el Tribunal Supremo, no exenta de razonabilidad, deja sin respuesta algunas cuestiones y crea incertidumbre sobre otras, las cuales pueden acrecentar, disminuir o hasta exonerar la responsabilidad administrativa, y que analizaremos a continuación siempre teniendo como punto de partida los salazones de Algeciras.

- Nulidad de la licencia.

La patrimonialización del aprovechamiento urbanístico se pone en duda cuando la licencia es nula por contradecir las normas sobre patrimonio histórico. En el caso que nos ocupa, el Ayuntamiento de Algeciras otorgó la licencia de obras pero, a diferencia del Tribunal Supremo, la sentencia de la Sala de Sevilla consideró que dicha licencia habria devenido nula, por cuanto el inicio del expediente de BIC suspendia la tramitación de licencias municipales y los efectos de las ya otorgadas. A nuestro humilde juicio, esta fundamentación adolece de toda consistencia, dado que no puede ignorarse que el interesado siguió con el procedimiento legalmente establecido, obteniendo la licencia para edificar. Por tanto, a pesar de la eventual nulidad de la licencia, el derecho al aprovechamiento urbanístico ya había sido adquirido, causando una lesión resarcible al no poder consolidarse la edificación.

- Responsabilidad de los entes locales.

La aludida circunstancia nos lleva, no obstante, a una cuestión nunca planteada por las partes ni por los órganos jurisdiccionales, que no es otra que las responsabilidades en las que podría haber incurrido el Ayuntamiento de Algeciras al continuar con los trámites y conceder la licencia para las 28 viviendas. Y es que la corporación local obvió el expediente de BIC hasta el punto de que en sesión de 25 de marzo de 2002, la Gerencia de Urbanismo acordó su otorgamiento por silencio positivo si en el plazo de un mes la Consejería de Cultura no llegaba a un acuerdo con el propietario para la adquisición del terreno. El Ayuntamiento amparaba su persistencia en el estricto cumplimiento de sus competencias urbanísticas, y en que la promotora pudiera interponer un recurso contra el retraso en su otorgamiento, que hasta entonces era de más de dos años.
El artículo 16 de la Ley de Patrimonio Histórico Español (y 36 de la Ley del Patrimonio Histórico de Andalucía en vigor) es tajante al advertir que la incoación de un expediente de declaración de BIC suspende la tramitación de las licencias, cualesquiera que sean. Esta declaración tuvo lugar un mes después de la concesión de la licencia. El Ayuntamiento, a priori, no habría actuado contra la ley, pero la invocación en el retraso de más de dos años en la concesión de la licencia carece de justificación para acelerar su trámite, porque según la Ley de Ordenación Urbanística de Andalucia el plazo máximo para su otorgamiento es de tres meses. Por otra parte, desde octubre de 2001 el Ayuntamiento tenía conocimiento, a través de la Consejería de Cultura, de la importancia del hallazgo y de las prospecciones que se estaban realizando.

Pues bien, el ejercicio de una competencia como la urbanística nunca debe entrar en conflicto con el patrimonio histórico, al constituir un bien superior protegido por el ordenamiento. Esta reflexión viene a subrayar que la entidad local procedió con pleno conocimiento de causa a la hora de conceder la licencia. Más aún cuando el expediente de BIC privaria de toda eficacia a la misma, y las obras ya estaban suspendidas por orden de la Consejería. Con esta actuación, el Ayuntamiento posibilitó deliberadamente que el aprovechamiento urbanistico fuese adquirido por el promotor. Sin embargo, no faltarán voces que se manifiesten a favor del estricto cumplimiento de las normas urbanísticas, si no se ha producido el inicio de la declaración de BIC, lo que es cuestionable, por cuanto han de valorarse todos los avatares que afectan a un expediente y descender al caso concreto. Polémicas aparte, de lo que no cabe duda es que en este tipo de asuntos relativos al patrimonio histórico, pueden coexistir responsabilidades de distintas administraciones públicas en el ejercicio de sus respectivas competencias, y no sólo de la autonómica.

- La actitud del hallador.

Aunque podría pasar desapercibido, un elemento esencial que puede atemperar al máximo la responsabilidad entronca con la actitud del titular de los terrenos que insta la indemnización, cuando como excepción a la regla general se ha silenciado el hallazgo con el fin de evitar la paralización de los trabajos. La ley obliga a comunicar los hallazgos casuales en un plazo de 24 horas. El principal problema que se suscita es si esa omisión se "transfiere" al dueño del terreno cuando terceras personas, como los empleados o el director de la obra, han sido los descubridores. El Reglamento sobre Patrimonio Histórico de Andalucía no deja lugar a dudas, al incluir en su artículo 83.2 a las empresas constructoras y promotores de forma solidaria, o lo que es lo mismo, el incumplimiento de uno debe ser soportado por el resto.

Hecha esta aclaración, veamos cómo se traduce la susodicha falta de comunicación en las reclamaciones por responsabilidad 


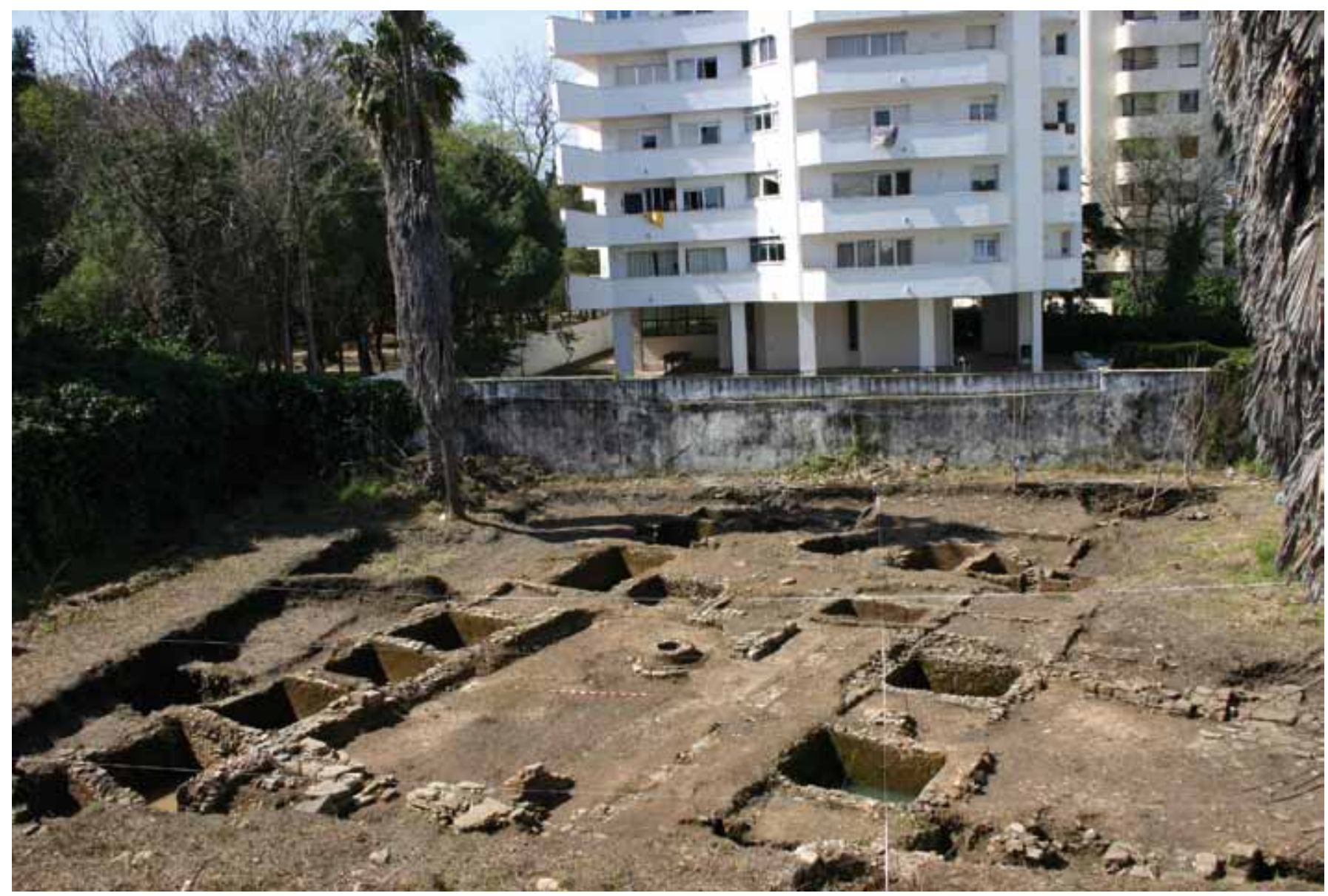

Salazones de Algeciras. Foto: D. Bernal (U. de Cádiz, Grupo HUM- 440)

patrimonial. La normativa sobre patrimonio histórico premia con una cantidad económica al hallador. De lo contrario, se le priva de dicho premio. Por lógica, esta misma consecuencia concurrirá cuando se invoque el derecho a indemnización y no se hubiera informado cumplidamente, debiendo soportarse la mala fe. Lo que no puede permitirse es transformar el instituto de la responsabilidad patrimonial en un negocio lucrativo dirigido a la obtención de un beneficio económico, cuando el descubridor se ha abstenido de su principal obligación ante un hallazgo de estas características. En consecuencia, y puesto que el interés público predomina sobre el privado, no sería amparable la actitud de quien clandestinamente ha impedido con su comportamiento dar a conocer la aparición de un resto arqueológico careciendo, por aplicación de un principio de justicia, de derecho alguno a indemnización.

\section{- Alternativas a la responsabilidad patrimonial.}

En otro orden de cosas y como ya se adelantó respecto a los salazones de Algeciras, la corporación local basó el retraso en la concesión de la licencia en el supuesto interés por la Consejería de Cultura para comprar el solar en el que se había producido el hallazgo. En la responsabilidad patrimonial el dueño del terreno se coloca en una situación activa y de preeminencia, pero aunque entran en juego muchos factores que pueden coartar sus ansias indemnizatorias, sería conveniente evitar llegar a un procedimiento judicial en el que se condene a abonar una cuantía susceptible de alcanzar cifras millonarias. En atención a ello, incluso de abrirse la vía de la responsabilidad patrimonial, una fórmula intermedia sería aquélla en la que la propia Administración acogiese la reclamación precisando la cuantía, siendo aceptada por el propietario. Pero surge la pregunta de si las administraciones públicas pueden barajar otras opciones. La respuesta es afirmativa.

Dejando a un lado la generosa y filantrópica posibilidad de una donación por el propietario, un simple contrato de compra-venta es suficiente para la adquisición del inmueble, lo que desde luego seria deseable al conjugarse la voluntad de ambas partes y convenir un acuerdo sobre el precio del terreno, quedando excluido el aprovechamiento urbanístico, y reduciéndose significativamente la cuantía frente a la responsabilidad patrimonial. Otra medida más rigurosa sería aquélla en la que la Administración actuara de forma unilateral, mediante el procedimiento especial para los bienes de valor artístico, histórico y arqueológico previsto en la Ley de Expropiación Forzosa, una vez se emita la declaración oficial de BIC. Aqui, el particular recibe una oferta elaborada por una comisión pericial formada por académicos. Como última medida, de estar en desacuerdo con el justiprecio, el propietario podrá acudir a los tribunales de orden contencioso-administrativo, circunscribiéndose el procedimiento a fijar la cuantía de la indemnización. 
Debido a su complejidad, los informes

periciales suelen encomendarse a

empresas tasadoras, que en el afán por

obtener la máxima cuantía posible, tienden a "hinchar" la reclamación

incluyendo partidas de lo más

extravagantes

La elección de alguna de estas dos alternativas a la responsabilidad patrimonial dependerá del ahorro y mejor utilización de los recursos económicos, a tenor de factores tales como la extensión del terreno, su precio de mercado, el proyecto de edificación y, sobre todo, la naturaleza e importancia del hallazgo. Pero lo cierto es que desde el punto de vista de satisfacción a los intereses generales, la compra-venta o la expropiación se antojan medios mucho más adecuados, no sólo a los efectos de evitar reclamaciones judiciales con visos de prosperar como el que nos ocupa, sino porque la Administración debería tomar la iniciativa cuando se trata de la protección del patrimonio cultural de mayor relevancia.

\section{- Ejecución de la sentencia.}

Llegamos finalmente al momento en que el órgano jurisdiccional decide sobre la responsabilidad patrimonial. Si el fallo judicial determina su existencia y fija la cuantía, la Administración ha de hacer frente al abono de la indemnización. Y es entonces cuando se advierte el lapso de tiempo transcurrido desde el momento en que tuvo lugar el hallazgo hasta la fecha de la sentencia. Téngase en cuenta que este tipo de procedimientos judiciales, en los que la cuantía reclamada puede superar con facilidad los 600.000 euros, son susceptibles de recurso de casación, es decir, que puede pasar por al menos dos instancias judiciales, lo que se traduce en varios años de proceso. Concretamente el promotor del solar donde fueron hallados los salazones de Algeciras ha tenido que esperar casi diez años desde su descubrimiento en el año 2002 hasta la resolución judicial ordenando la ejecución de la sentencia en 2011.

Esta dilación, de estimarse la demanda, conllevaria la necesidad de actualizar la indemnización para evitar una pérdida de valor adquisitivo, a lo que han de añadirse los intereses, acrecentándose de manera considerable la cantidad inicialmente solicitada por el propietario. Estos nuevos cálculos se integran en un procedimiento en sí mismo, denominado incidente de ejecución, con el consiguiente nuevo retraso que ese incidente origina. Su densa prolongación en el tiempo y la volubilidad de la indemnización son caracteristicas que impregnan este tipo de reclamaciones, revirtiendo tanto en el propietario como en la Administración demandada.

\section{VALORACIÓN DE LOS PERJUICIOS: EL INFORME PERICIAL}

Es evidente que el propietario que ha sido privado del derecho a edificar habrá sufrido perjuicios de todo tipo, pero siempre tiene que responder a un daño efectivo y acreditarse con datos, fechas, facturas, fotografías y otros documentos, lo que sólo se logra en conjunción con un selecto informe pericial que dé solidez a la reclamación. Debido a su complejidad, estos informes suelen encomendarse a empresas tasadoras, que en el afán por obtener la máxima cuantía posible, tienden a "hinchar" la reclamación incluyendo partidas de lo más extravagantes. Será la Administración la encargada de desvirtuarlo, y cuanto más motivado esté, más difícil será la tarea. De ahí la importancia de un buen informe pericial en la valoración de los daños. Como regla general, los informes deben enfocar sus apreciaciones a los perjuicios económicos causados por el hallazgo, pero su primer punto débil reside en que suelen emitirse con el inciso de que se han utilizado parámetros para préstamos hipotecarios, por lo que carecen de la debida exactitud, al no ser comparable una tasación hipotecaria con una responsabilidad patrimonial.

Dicho esto, comenzando por los gastos que en ningún caso pueden ser admitidos (además de los no justificados), han de incluirse aquellos que se realizaron con anterioridad, al menos, a la suspensión de las obras tras el hallazgo, y los que se hubieran comprometido indistintamente de no haberse limitado el derecho a construir. Pertenecen a este grupo los estudios de viabilidad, inscripciones registrales, cualquier clase de licencia (demolición, construcción, apertura, etc.), informes ambientales $y_{1}$ por supuesto, tasas e impuestos. El coste de los estudios arqueológicos tampoco podrán ser objeto de valoración, al ser preceptivos. Los gastos efectuados en el seno del procedimiento judicial, como los honorarios profesionales de abogado y procurador, se regirán por las normas atinentes a las costas procesales.

Con todo, el grueso de todas las reclamaciones es el lucro cesante, esto es, las ganancias futuras que se han dejado de obtener, pero sólo las esperadas conforme al normal desarrollo de los acontecimientos, y no las meras expectativas. El lucro cesante se genera por la frustración de no poder materializar la edificación (aprovechamiento urbanístico), y los beneficios futuros derivados de la misma, como sería el precio de la venta, el alquiler o el uso de instalaciones si estaba proyectado un hotel o un establecimiento de servicios. Por otra parte, es impensable aceptar una indemnización por lucro cesante basada exclusivamente en los beneficios que podrian haberse alcanzado, sin incluir el más mínimo gasto, ya que la generación de un beneficio siempre está sujeta a una amortización. 0 dicho de otro modo, el binomio ganancia-gasto es inseparable, y un informe pericial que no lo contemple no se ajustará a la realidad. La puerta que abre al ingenio requiere de una actividad probatoria muy exigente, y es esencial que el informe incluya una relación pormenorizada y motivada de los presuntos beneficios. 
Por último, no podemos concluir sin hacer una mención a los daños morales, que engloban todos los perjuicios inmateriales o psicológicos, o simplemente los de difícil encuadre, entre los que podemos citar como típico el presunto menoscabo en la reputación de la promotora por no poder consolidar la edificación. Si el lucro cesante requiere de una gran afinación, este tipo de daños aún más por su vacuidad, suele ser desestimado por los tribunales en la mayor parte de los casos.

\section{RESUMEN Y REFLEXIÓN FINAL}

Aunque pueden presentarse infinidad de supuestos, según la jurisprudencia, con carácter general, los requisitos para que nazca el derecho a exigir una indemnización por la vía de la responsabilidad patrimonial son los siguientes: que se produzca el hallazgo de un resto arqueológico y la incoación de un $\mathrm{BIC}$; que el planeamiento no contenga previsiones que condicionen la construcción en una zona protegida; y que se limite el aprovechamiento urbanístico ya adquirido por el propietario con la licencia para edificar. Pero tras estos presupuestos, como hemos visto, se esconde una amalgama de variables que inciden directamente en el nexo que imputa la responsabilidad a la Administración, así como en la cuantía indemnizatoria, cuya verosimilitud dependerá de la calidad del informe pericial que se aporte.

En la situación actual, el instituto de la responsabilidad patrimonial se ha instaurado como fuente principal para resarcir los perjuicios que ocasionan los límites a la edificación por un hallazgo casual. Pero la clave para el optimismo reside en pensar que la protección del patrimonio histórico y la propiedad privada no son incompatibles. Sólo hay que buscar un punto de encuentro entre ambos para lograr un equilibrio que satisfaga los intereses públicos, y evite en la medida de lo posible lesionar los derechos de los particulares.

\section{Normativa}

DECRETO 231/2003, de 18 de noviembre, del Consejo de Gobierno, por el que se declara Bien de Interés Cultural con la categoría de Zona Arqueológica, las Factorias Romanas de Salazones de Algeciras (Cádiz). Boletín Oficial de la Junto de Andalucía, n. ${ }^{\circ} 245$, de 22 de diciembre de 2003

LEY 16/1985, de 25 de junio, del Patrimonio Histórico Español. Boletín Oficial del Estado, n. ${ }^{\circ}$ 155, de 29 de junio de 1985

LEY 7/2002, de 17 de diciembre, de Ordenación Urbanística de Andalucia. Boletín Oficial de la Junta de Andalucía, n. ${ }^{\circ}$ 154, de 31 de diciembre de 2002

LEY 1/1991, de 3 de julio, de Patrimonio Histórico de Andalucía. Boletín Oficial de la Junta de Andalucía, n. ${ }^{\circ}$ 59, de 3 de julio de 1991

LEY 30/1992, de 26 de noviembre, de Régimen Juridico de las Administraciones Públicas, y del Procedimiento Administrativo Común. Boletín Oficial del Estado, n. ${ }^{\circ} 285$, de 27 de noviembre de 1992

LEY 29/1998, de 13 de julio, reguladora de la Jurisdicción ContenciosoAdministrativa. Boletín Oficial del Estado, n. ${ }^{\circ}$ 167, de 14 de julio de 1998 REGLAMENTO de Protección y fomento del Patrimonio Histórico de Andalucia, aprobado por Decreto 19/1995, de 7 de febrero. Boletín Oficial de la Junta de Andalucía, n. ${ }^{\circ}$ 43, de 17 de marzo de 1995

REGLAMENTO del Patrimonio de la Comunidad Autónoma de Andalucia, aprobado por Decreto 276/1987, de 11 de noviembre. Boletín Oficial de la Junta de Andalucía, n. ${ }^{\circ}$ 2, de 8 de enero de 1998
REGLAMENTO de la Ley de Expropiación Forzosa, aprobado por Decreto 26 de abril de 1957. Boletín Oficial del Estado, n. 160, de 20 de junio de 1957 REGLAMENTO de los Procedimientos de las Administraciones Públicas en Materia de Responsabilidad Patrimonial, a probado por Real Decreto 429/1993, de 26 de marzo. Boletín Oficial del Estado, n. 106, de 4 de mayo de 1993

\section{Jurisprudencia}

SENTENCIA del Tribunal Supremo, de 9 de diciembre de 2011, recurso n. ${ }^{\circ}$ $6569 / 2009$

SENTENCIA del Tribunal Supremo, de 15 de diciembre de 2010, recurso n. ${ }^{\circ}$ $1336 / 09$

SENTENCIA del Tribunal Supremo, de 25 de junio de 2003, recurso n. ${ }^{\circ}$ 6754/2000 SENTENCIA del Tribunal Superior de Justicia de Andalucia, sede de Sevilla, de 29 de diciembre de 2008 , recurso n. ${ }^{\circ} 847 / 05$ 